Regular Research Article

\title{
Traditional usage of medicinal plants by Temiar tribes in the State of Kelantan, Peninsular Malaysia
}

\author{
Pakhriazad Hassan Zaki ${ }^{1 *}$, Seca Gandaseca ${ }^{1}$, Noorhayati Mohd Rashidi ${ }^{1}$, Mohd Hasmadi Ismail ${ }^{1}$ \\ ${ }^{1}$ Faculty of Forestry, Universiti Putra Malaysia, 43400 UPM Serdang, Malaysia \\ * Correspondence author: pakhriazad@upm.edu.my; asato40@hotmail.com
}

\begin{abstract}
Traditional medicine has deep historical linkages and cultural roots. In a rural community, it is practice based on the ethnological, medical and heritage of the practitioners. Temiar indigenous tribe of Orang Asli in Kelantan, have their traditional way of beliefs and healing practices. This study examines the remedies using medicinal plants and herbs among the tribe members in Kampung Pasik, Kelantan, Malaysia. A structured questionnaire and in-depth interviews were conducted with 250 respondents. A total of 18 species of medicinal plants was recorded preferably used by the tribes. Results indicate that traditional phytoremedies practices play an important role in helping their healthcare system with the help of the tribe healers. Cultivated medicinal plant species represent $94 \%$ of the source, whereas $4.4 \%$ were found wild in the forest and $1.6 \%$ grown around their settlement. This study revealed that five preparations methods such as boiling $(27.56 \%)$, pounded $(27.45 \%)$, squeeze $(21.60 \%)$, drying $(14.17 \%)$ or concoction of various part of medicinal plants (9.22\%). The most applied were by drinking $(35.29 \%)$, chewing $(32.70 \%)$ and $19.89 \%$ rubbing, poultice $(6.40 \%)$ and shower ingredients $(5.72 \%)$.
\end{abstract}

Keywords: Ingredients; indigenous people; medicinal plants; traditional use.

\section{Introduction}

Medicinal plants are the local heritage in many developing countries (Igdir et al., 2013). In many Asian countries traditional medicine to be widely used, even though allopathic medicine is often readily. Traditional medicine, also known as indigenous or folk medicine comprises medicinal knowledge systems that developed over generations with various societies before the era of modern medicine (Gunjan et al, 2012). In Malaysia, traditional forms of Malay, Chinese and Indian medicine are used extensively (WHO, 2002). Malaysia has an abundance of species of flowering and non-flowering plants of medicinal value (Zaidah et al, 2006). Its play an important role among the rural community as medicine sources to cure common disease. The rural community normally lives in remote and difficult geographical areas in the country. They highly depend on flora and faunas for food and traditional medicine to survive.

Medicinal plants used mostly derived wildly from forest or self-cultivated. Nowadays, the usages of medicinal plants as traditional medicine increased due to awareness of the effectiveness to cure the diseases. Various methods are used in the treatment of illnesses, including herbal medicines such as spices, plants and animals (Jamal et al, 2011). Most of technical knowledge and method of preparation usually inherited by generations without proper documentation. Documentation of traditional knowledge of medicinal plants is still on-going in Peninsular Malaysia (Ong et al., 2011a,b). Orang Asli is one of the forest dependence communities which still depend on it as sources of medicine and to cure spiritual illness (Samuel et al, 2010).

\subsection{Medicinal plant use in traditional medicine}

Medicinal plants play an important role in traditional communities (Monteiro et al, 2006). In the biological sciences, the use of medicinal plants in indigenous cultures is commonly seen as being based on a long tradition or 'traditional medicine' (Leonti et al., 2003). Plants used in traditional medicine have an important role to play in the maintenance of health in all parts of the world and in the introduction of new treatments (Peter and Pharm, 2011). Much of the wealth of a 
country resides in its plant inheritance, whether the plants are endemic, naturalized or recent introductions (Mitchell and Ahmad, 2006). Traditions medicine like "Traditional" Chinese, Ayurvedic, Unani, Jamu, Kampo, Iranian, Aztec or various forms of European and Arabic medicine are well-known examples of traditional medication practices (Heinrich, 2010).

The selection of any medicinal plants a closely guided secret and is usually kept within the family (Molik, 2012). However, for cultures with no written records, there is practically no evidence available to establish the historical depth of traditional medicinal plant use (Coxis, 2000). In other regions, the efforts of researchers past and present to document such knowledge and to critically analyze the data are important (Heinrich, 2010). The documentation of such plants can help preserve indigenous knowledge about traditional medicines for future generations and identify plant species for future pharmacological and phytochemical research (Asiime et al, 2013).

\subsection{Role of traditional medicine in communities}

A large population of people in the developing countries depends on traditional medicine for their primary health care (Awodele et al, 2011). The World Health Organization (WHO) (2000) defines traditional medicine as "the sum total of knowledge, skills and practices based on the theories, beliefs and experiences indigenous to different cultures that are used to maintain health, as well as to prevent, diagnose, improve or treat health and physical and mental illnesses. Cheung, (2011) defines traditional medicine as a system of ancient medical practice that differs in substance, methodology and philosophy of modern medicine and it plays an important role in health maintenance for the peoples of Asia, and it is becoming more frequently used in countries in the West. Researchers believe that traditional medicine is used by many people to manage conditions (Gyasi et al., 2011).

Traditional medicine usually involves biological resources and the knowledge of local and indigenous peoples and/or healers regarding their medicinal use; thus, it is interlinked with biodiversity conservation and indigenous peoples' rights over their knowledge and resources (Timmermans, 2003). The study of traditional medicines and their manufacture has much to offer to sociocultural studies of many medical systems. Medicines constitute a meeting point of almost any imaginable human interest: material, social, political and emotional (Geest, 2006). They use plants for food, handicrafts, construction, as a primary energy source and even for medicinal purposes (Matavele and Habib, 2000). This traditional culture disappears day by day due to the improving economic opportunities or migration (Kaval et al, 2014). Successful integration of traditional medicine into the mainstream health care delivery system requires an understanding of traditional medicine practitioner's recruitment modes and practices (Tabuti et al, 2003). Recovering ancient knowledge is very important for preserving ethno-biodiversity and to discover new entities for further evaluation of their biological activity (Menale and Muoio, 2014).

The Orang Asli has been categorized linguistically into three groups, namely; Northern Aslian, Central Aslian and Southern Aslian (Riddick and Daniel, 1983). They are divided into Negritos, Semai, Temiar, Jakun and Proto-Malays. In the state of Perak and Pahang, the Temiar and Negrito group also known as Semang. The Negritos include the Batik and Mendrik communities of Kelantan and the Jahai or northern Perak.

\section{Materials and methods}

\subsection{Study area}

The study was conducted at Temiar group of Orang Asli settlement in Kampung Pasik, Kelantan from January to March 2018. This settlement is located nearby the district of Gua Musang $4^{\circ} 53^{\prime} 0^{\prime \prime} \mathrm{N}, 101^{\circ} 58^{\prime} 0^{\prime \prime} \mathrm{E}$ consist of 500 populations (Figure 1). 


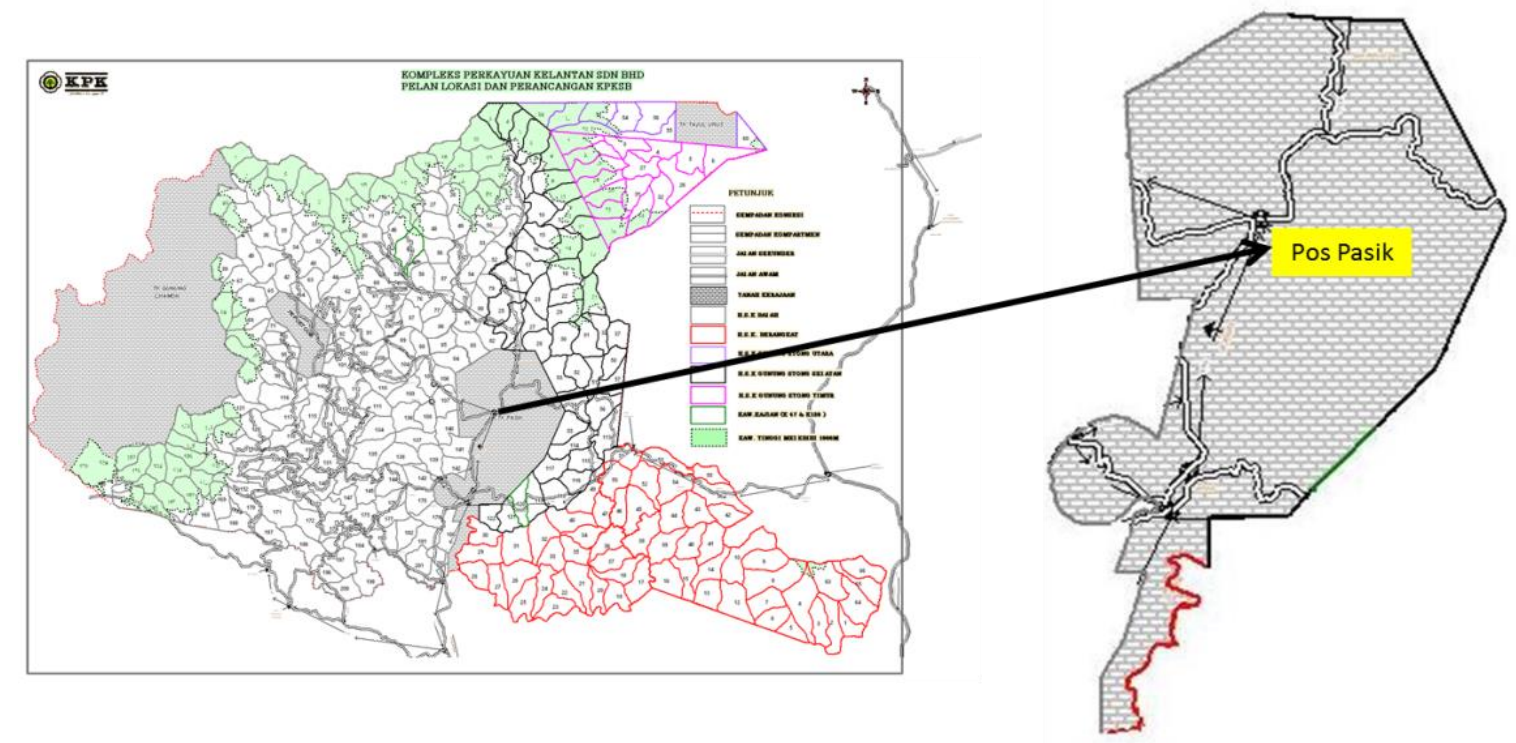

Figure 1. A map of the study area showing Pos Pasik in Kelantan state, Malaysia.

\subsection{Data collections}

In this study, three types of data collection were employed; namely by questionnaire survey, in-depth interview and site observation. A total of 250 respondents was selected by cluster sampling; using structured questionnaires, in-depth interviews and site observation. The respondents were male and female, ranging from 18 to 40 years old and above. Most of the respondents were attended secondary school (46.9\%), 29.2\% attended primary school while others were illiterate (23.8\%). Questionnaires distributed by cluster sampling as a result of dispersed population and geographical constraints. The questionnaires consisted of three main sections; i) demographic information, ii) usage of medicinal plants; and iii) type of medicinal plant used.

In-depth interviews were conducted with traditional healers based on their knowledge on the use of medicinal plants. The healers were those professional practitioners who medicate the local people using the local plants by using ethno medicinal plants and their products (Yineger and Yewhalaw, 2007). Site observation was conducted to study how the traditional healers collect and prepare the medicinal plants to treat ailments.

\subsection{Data analysis}

Descriptive analysis, chi-square $\left(\mathrm{X}_{2}\right)$ tests and cross tabulation analysis were run in SPSS 20.0 to analyze data. The descriptive analysis was used to analyze demographic data in order to obtain frequency, mean and percentage. Tabulation analysis was used to determine the relationship between types of the plant commonly used by the Temiar. Lastly, chi-square was used to determine the significant variation on the type of preparation techniques to prepare the medicine by marital status.

\section{Results}

This study indicates that the Temiar tribes still practice traditional phytoremedies using medicinal plants. The role of traditional healers and shamans to preserve this culture is still strong in the Temiar community. The traditional healers play an important role in helping the indigenous health care system. The Temiar practiced the traditional method of health care due to the little 
access from their village to get medicinal treatments. The government medical group only came once per month to give a treatment. Several of them couldn't afford the cost of modern medications. On the other hand, some of the villagers still using traditional phytoremedies even they can afford better medications for modern health services due to their beliefs.

A total of 250 villages from the subgroup of Temiar community have participated in this survey. A significant (Spearman correlation test, $r=0.34, \alpha=0.01, p=0.00$ ) correlation was observed between the numbers of species reported by aborigines and the education of respondents. Moreover, the spearman correlation test also shows significant (Spearman correlation test, $r=0.47, \alpha=0.01, p=0.00$ ) result between the numbers of species reported by aborigines and the age of respondents. Five common human ailments were identified by the indigenous of the study site. Eighteen traditional plant species were reported as common plants used by aborigines as medicine. Fifteen botanical families were identified; Zingiberacea was the most represented families in medicinal plant species used followed by Rutaceae, Euphorbiaceae, Annonaceae, Umbellifeae, Smilacaceae, Mysinaceae, Simaroubaceae, Polyporaceae, Asteraceae, Poaceae, Solanaceae, Caesalpinaceae, Asteraceae, and Piperaceae.

The medicinal plant species cited in this study area were $94 \%$ cultivated. A total of $4.4 \%$ of the species found wild in the forest and $1.6 \%$ of species were grown wild surrounded the settlement. A significant $(\chi 2=16.22, d f=4, \alpha=0.005, p=0.003)$ differences were observed between the distribution of medicinal plants and diversity of medicinal plants in the area. Plants were harvested for their root $(59.47 \%)$, leaves $(22.74 \%)$, rhizome $(13.70 \%)$ and fruits $(4.09 \%)$. Plant part to prepared remedies also show significant differences $\left(\chi^{2}=46.11, \mathrm{df}=6, \alpha=0.005, \mathrm{p}=0.000\right)$ with the diversity of medicinal plants. Distribution of preparation method was by boiling $(27.56 \%)$, pounded $(27.45 \%)$, squeeze $(21.60 \%)$, drying $(14.17 \%)$ and a concoction of various part of medicinal plants (9.22\%) (Figure 2).

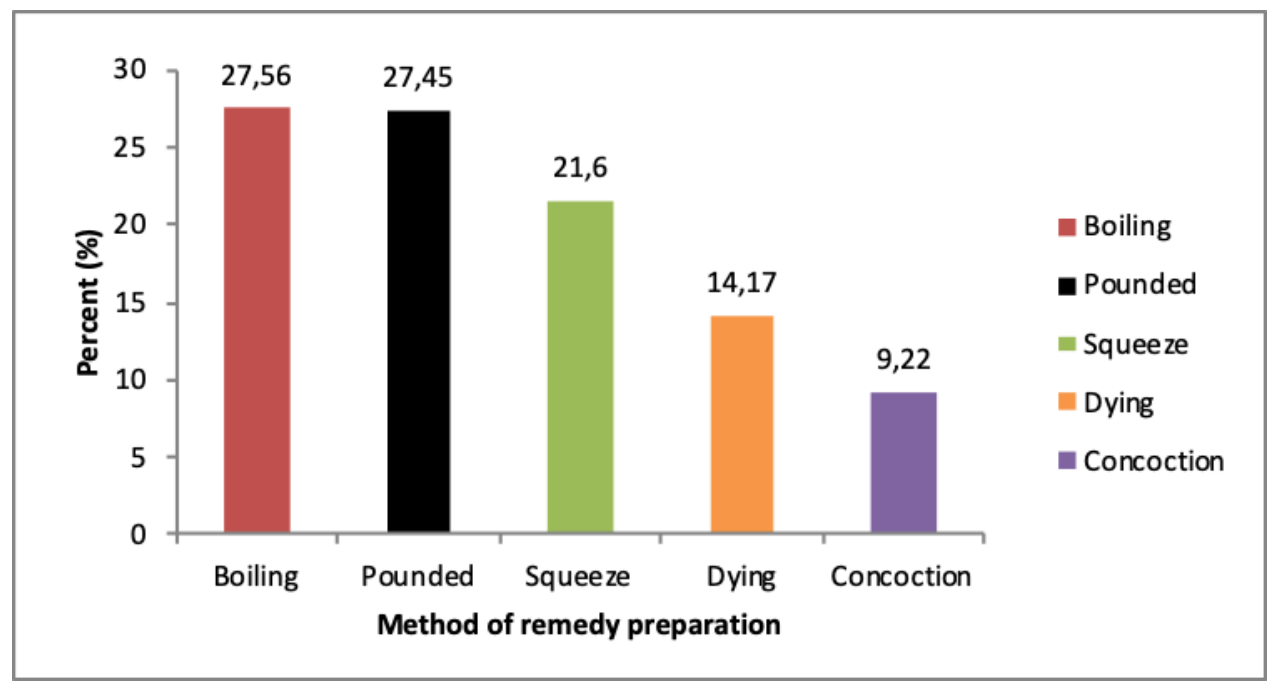

Figure 2. Method use by indigenous in remedy preparation.

The result revealed that drinking (35.42\%) and eating $(32.70 \%)$ were the most popular method of usage. Whereas $(19.89 \%)$ of the respondents claim that rubbing was the remedy application used by their community. Only a few stated poultice $(6.40 \%)$ and as shower ingredients $(5.72 \%)$ (Figure 3$)$. Several medicinal plant species have similarly used for the same illness. Remedies for skin wounds and scab can be prepared by crushing fresh whole part of Dhyllanthus niruni and mixed with cold water. Squeezed of Centella asiatica (L.) Urban water can apply orally 
to affected skin. Poultice of Centella asiatica (L.) Urban leaves can treat sores and pound of fresh leaves into a paste to apply it to the body for fever. Their women claimed the leaves of Centella asiatica (L.) Urban also believed good for the afterbirth.

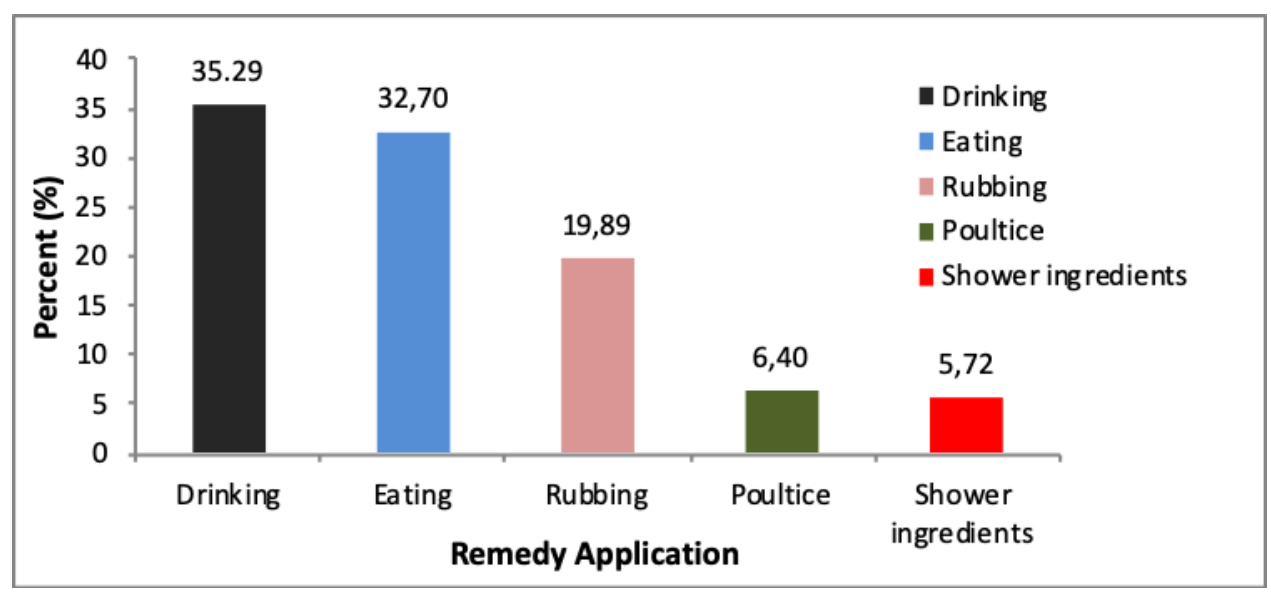

Figure 3. Type of remedy application by the Temiar tribes.

Smilax myosotiflora were reported traditionally using as medicine to increase the strength of male energy by boiling tuber chip and extract to drink along with honey or rock sugar to reconcile. Similarly, boiling the whole Labisia pumila in water and extract to drink was reported to regain mother strength after birth and it also hastens the delivery of their babies by concoction made from. Drying chips root of Eurycoma longofolia was boiled and extract to drink can relief fever, increase vitality and sexual function of the male. Paste prepared from pounded of Zingiber officinale rhizomes were directly applied over the sprained area to avoid it swelling. They also report Curcuma domestica Loir was traditionally used for treating sprain and swelling by form paste and mixing turmeric salt, Citrus aurantifolia juice and apply externally to an affected area. Fresh crushes mushroom of Lignosus rhinoceros were mixed with water and drink to relieve flu and fever. The fresh root of Goniothalamus macrophyllus also helps relieve fever. Drinking extract from boiling root of Goniothalamus macrophyllus is one way of postnatal care. Young leaves of Chromolaena odorata were crushed and resulting liquid that can be used to treat skin wounds. Extractions of Cymbopogon nardus were used in the bath by mother after childbirth to refresh body skin. Temiar drink extraction from boiling Solanum torvum fruit to relieve stomach ache.

Fresh leaves of Cassia alata were reported to be pounded and rubbed directly on the skin to cure ringworm and white spot infection. The juices of boiled Zingiber zerumbet rhizome were used to treat worm infection in children. Fresh leaves of Blumea balasamifera were pounded and crush and apply directly around the area to the throbbing area. Piper betle leaves were pounded into paste and applied to wounds, swelling and ulcers. Murraya koenigii fruit is boiled in Cocos nucifera oil until blackness can be crushed are used to treat insect bites and poisonous animals. The villagers believed in spiritual power and used several medicinal plants during the treatment. They believed leaves and fruit of Citrus aurantifolia can drive away evil spirits from the patient's body.

\section{Discussion}

The result of this study showed that traditional phytoremedies using medicinal plant species still been practices to treat human ailments, even though modern health care facilities were provided. Although a few of the remedies are strong, all can be used safely and without the side effects of the drug. Most of the traditional phytoremedies were practices of a rural community 
who live near to sources of medicinal plants. These studies indicate that most of the medicinal plant species were cultivated and a few numbers of plants were found in the forest. Several forests near to the Temiar settlement were converted to palm oil plantation and other areas were logging area. Due to this issue, the aborigines tend to cultivate the medicinal plants near their settlement. Some plants are native in the forest or another natural habitat is also planted by them in the village (Ong et al., 2011a,b).

The indigenous knowledge on preparing the medicine was passed down to indigenous from the old generation by orally without any documentation. Most of the respondent claims, they only identify the type of medicinal plants and used when they involve with old people or traditional healers during the plants and remedies preparation. They also have poor knowledge of dosage while preparing the remedies to their patients and most of remedies adverse effect except vomiting and temporary inflammations (Yineger and Yewhalaw, 2007). Most of the indigenous knowledge was practiced by married respondents compared to a single respondent. This could be attributed to age, as married respondents are older than the single respondents so they are more access to indigenous knowledge rather than the single respondents who were younger. Several respondents have little concern on the value of indigenous knowledge and they only used it for their own sake and not transfer it to others.

\section{Conclusions}

This study indicates the traditional knowledge of preparation remedies using medicinal plant were still used even though they were an effort with modern medication which gives a better service on their health. Most of the preparation, application and part used of medicinal plants in the present study are very similar to those in other communities in Malaysia (Ong et al., 2011a,b). Lack of numbers and interest among young generations of practicing the folk traditional will bury valuable knowledge through time. In a world with limited financial resources, it seems currently impossible to screen each of the unexplored species for the biological activity of their compounds. Hence, in order to save knowledge on pharmaceutical and medical usability of plants from loss, some kind of affordable and effective survey strategy is needed. The ethnobotanical approach is one such method that meets this requirement and can be applied to select plants for pharmacological studies (Šarić-Kundalić et al, 2010).

Conflicts of Interest: The authors declare no conflict of interest

\section{References}

Asiimwe, S., Mugisha, M. K., Namutebi, A., Karlsson, A. K. B. and Musiimenta, P. (2013). Ethnobotanical study of nutri-medical plants used for the management of HIV/AIDS opportunistic ailments among the local communities of western Uganda. Journal of Ethopharmacology, 15 (2), 639-648. doi: https://doi.org/10.1016/j.jep.2013.09.017

Awodele, O., Agbaje, E. O., Ogunkeye, F. A., Kolapo, A. G. and Awodele, D. F. (2011). Towards integrating traditional medicine (TM) into National Health Care Scheme (NHCS): Assessment of TM practitioners' disposition in Lagos, Nigeria. Journal of Herbal Medicine, 1(3-4), 90-94. doi: https://doi.org/10.1016/j.hermed.2011.09.002

Cheung, F. (2011). TCM: Made in China. Nature, 480(7378); S82-S83. doi: https://doi.org/10.1038/480S82a

Coxis, P. A. (2000). Will tribal knowledge survive the millennium? Science, 288(5450), 44-45. doi: https://doi.org/10.1126/science.287.5450.44 
Geest, S. V. D. 2006. Anthropology and the pharmaceutical nexus. Anthropological Quarterly, 79(2), 303-14.

Gunjan, M., Karna, L., Dayalan, K. and Sasigaran, P. (2012). A review and research of phytomedicine used by traditional people of Malaysia (Ipoh, Perak). International Journal of Phytotherapy Research, 2(3), 26-41.

Gyasi, R. M., Mensah, C. M., Ei, P. O. A. and Agyemang, S. (2011). Public perception of the role of traditional medicine in the health care delivery system in Ghana. Global Journal of Health Science, 2(2), 40-49.

Heinrich, M. (2010). Ethnopharmacology in the $21^{\text {st }}$ century-Grand challenges. Frontiers in Pharmacology, 1, 8. doi: https://doi.org/10.3389/fphar.2010.00008

Heinrich, M. 2010. Ethnopharmacology in the 21st century - grand challenges. FRONTIERS IN PHARMACOLOGY, 1, 8 http://dx.doi.org/10.3389/fphar.2010.00008 .

Igdir, H. B., Rezai, M. R. and Hoseini, M. 2013. The packaging state of Iranian medicinal-plants in view of their production exports. Advanced Crop Science, 3(2), 181-190.

Jamal, J. A., Ghafar, Z. A., \& Husain, K. (2011). Medicinal plants used for postnatal care in Malay traditional medicine in the Peninsular Malaysia. Pharmacognosy Journal, 3(24), 15-24. doi: https://doi.org/10.5530/pj.2011.24.4

Kaval, I., Behçet, L., \& Cakilcioglu, U. (2014). Ethnobotanical study on medicinal plants in Geçitli and its surrounding (Hakkari-Turkey). Journal of Ethnopharmacology, 155(1), 171-184.doi: https://doi.org/10.1016/j.jep.2014.05.014

Kaval, I., Behcet, L. and Cakilcioglu, U.2014. Survey of wild food plants for human consumption in Gecitli (Hakkari, Turkey) Indian. J Tradit Know, 14(2), 183-190.

Leonti, M., Sticher, O., \& Heinrich, M. (2003). Antiquity of medicinal plant usage in two MacroMayan ethnic groups (Mexico). Journal of ethnopharmacology, 88(2-3), 119-124. doi: https://doi.org/10.1016/S0378-8741(03)00188-0

Matavele, J., \& Habib, M. (2000). Ethnobotany in Cabo Delgado, Mozambique: use of medicinal plants. Environment, Development and Sustainability, 2(3-4), 227-234. doi: https://doi.org/10.1023/A:1011414124429

Menale, B., \& Muoio, R. (2014). Use of medicinal plants in the south-eastern area of the partenio regional park (Campania, southern Italy). Journal of ethnopharmacology, 153(1), 297-307. doi: https://doi.org/10.1016/j.jep.2014.02.039

Mitchell, S. A., \& Ahmad, M. H. (2006). A review of medicinal plant research the University of the West Indies, Jamaica, 1948-2001. West Indian Medical Journal, 55(4), 243-269.

Molik, M. 2012. Removal of one or more arsenic related infections by using medicinal plants: findings from a rapid assessment study in Satkhira district of Bangladesh. Complementary and Alternative Medicine, 12(1) 429, doi: https://doi.org/10.1186/1472-6882-12-S1-P429 .

Monteiro, J. M., de Albuquerque, U. P., de Freitas Lins-Neto, E. M., de Araújo, E. L., \& de Amorim, E. L. C. (2006). Use patterns and knowledge of medicinal species among two rural communities in Brazil's semi-arid northeastern region. Journal of Ethnopharmacology, 105(1-2), 173-186. doi: https://doi.org/10.1016/j.jep.2005.10.016

Ong, H. C., Ahmad, N., \& Milow, P. (2011a). Traditional medicinal plants used by the temuan villagers in Kampung Tering, Negeri Sembilan, Malaysia. Studies on Ethno-Medicine, 5(3), 169-173.doi: https://doi.org/10.1080/09735070.2011.11886406

Ong, H. C., Zuki, R. M., \& Milow, P. (2011b). Traditional knowledge of medicinal plants among the Malay villagers in Kampung Mak Kemas, Terengganu, Malaysia. Studies on Ethnomedicine, 5(3), 175-185. doi: https://doi.org/10.1080/09735070.2011.11886407

Peter, J. H. and B. P. (2011). The role of plant in traditional medicinal and current therapy. The Journal of Alternative and Complementary Medicine, 95, 1(2): 131-143. 
Riddick, C. C., \& Daniel, S. N. (1984). The relative contribution of leisure activities and other factors to the mental health of older women. Journal of Leisure Research,16(2), 136-148.doi: https://doi.org/10.1080/00222216.1984.11969581

Samuel, A.J., Kalusalingam, A., Chellappan, D., K., Gopinath, R., Radhamani, S., Husain, H, A, Muruganandham, V, and Promwichit, P. (2010). Ethnomedical survey of plants used by the Orang Asli in Kampung Bawong, Perak, West Malaysia, J Ethnobiol Ethnomed, 7, 6:5. doi: https://doi.org/10.1186/1746-4269-6-5

Šarić-Kundalić, B., Dobeš, C., Klatte-Asselmeyer, V., \& Saukel, J. (2010). Ethnobotanical study on medicinal use of wild and cultivated plants in middle, south and west Bosnia and Herzegovina. Journal of Ethnopharmacology, 131(1), 33-55. doi: https://doi.org/10.1016/j.jep.2010.05.061

Tabuti, J. R. S., Dhillion, S. S. and Lye, K. A. (2003). Traditional medicine in Bulamogi country, Uganda: Its practitioners, users and viability. Journal of Ethnopharmacology, 85(1), 119-129.

Timmermans, K. 2003. Intellectual property right and traditional medicine: policy dilemmas at the interface. Social Science \& Medicine, 57(4), 745-756.

World Health Organization (WHO). (2000). General Guidelines for Methodologies on Research and Evaluation of Traditional Medicine. Retrieved July 4, 2013, from / http://whqlibdoc.who.int/hq/2000/WHO_EDM_TRM_2000.1.pdf?ua=1.

World Health Organization (WHO). (2002). WHO Traditional Medicine Strategy 2002-2005. Geneva. World Health Organization.

Yineger, H. and Yewhalaw, D. (2007). Traditional medicinal plant knowledge and use by local healers in Sekoru District, Jimma Zone, Southwestern Ethiopia. Journal of Ethonobiology and Ethomedicine, 3:24, doi: https://doi.org/10. 1186/1746-4269-2-24 .

Zaidah, R., Aizi, N. M. R., Izza, A. A., Liew, W. M., Noor, A. A. F., Nor, F. M. Z., Nor K. K., Pua, S. S., Azrul, R. M., Siti, M. M. D. and Zahirah, Z. (2006). Genomic extraction of several Malaysian herbal plants. In: Proceedings of Annual Fundamental Science Seminar, $6^{\text {th }}$-7th June 2006, Universiti Teknologi Malaysia, Skudai, Malaysia. 